\title{
Study on Nasal Tip Projection of South Indian Population to derive Reference Values for Corrective Nasal Surgeries
}

\author{
${ }^{1}$ Geetha K Siddapur, ${ }^{2}$ Kishan R Siddapur
}

\section{ABSTRACT}

Aim: The present study was taken up with an objective to derive reference values in relation to nasal tip projection (NTP) of Tamil Nadu population.

Materials and methods: The present study was conducted with the approval of the Institutional Ethics Committee. A total of 118 medical students from Velammal Medical College Hospital and Research Institute, Madurai, Tamil Nadu, India, participated in the study. Consenting students were included and individuals with noticeable facial disfigurement and with history of previous facial surgery were excluded. Goode method was used to analyze NTP.

Results: The present study reports NTP of 0.65 (0.66 in males and 0.64 in females) with standard deviation (SD) of 0.06 in South Indian population of Tamil Nadu region.

Conclusion: Nasal tip projection can be considered as a ratio that can be used while planning corrective nasal surgeries, and can be used in a simple and effective manner than other parameters like nasal angles and indices, and nasal morphology.

Clinical significance: The present study results will help surgeons avoid complications by anticipating the healing forces and take into account support mechanisms of the nasal tip when planning an optimal approach for esthetic nasal surgeries on patients, especially of our geographical area, and of the ethnic group that has been studied on. Also, surgeons from other parts of the world can use the present study results as reference while planning similar surgeries.

Keywords: Clinical, Corrective nasal surgeries, Nasal tip projection, Rhinology.

How to cite this article: Siddapur GK, Siddapur KR. Study on Nasal Tip Projection of South Indian Population to derive Reference Values for Corrective Nasal Surgeries. Clin Rhinol An Int J 2017;10(3):128-131.

Source of support: Nil

Conflict of interest: None

\footnotetext{
${ }^{1,2}$ Associate Professor

${ }^{1}$ Department of ENT, Velammal Medical College Hospital \& Research Institute, Tamil Nadu Dr. MGR Medical University Madurai, Tamil Nadu, India

${ }^{2}$ Department of Forensic Medicine, Velammal Medical College Hospital \& Research Institute, Tamil Nadu Dr. MGR Medical University, Madurai, Tamil Nadu, India

Corresponding Author: Geetha K Siddapur, Associate Professor, Department of ENT, Velammal Medical College Hospital \& Research Institute, Tamil Nadu Dr. MGR Medical University, Madurai, Tamil Nadu, India, Phone: +919500585290 e-mail: drgeetabm@gmail.com
}

\section{INTRODUCTION}

Nose shape plays a vital role for an individual's facial appearance. It is not uncommon to find people opting for cosmetic nasal surgeries these days. But for a surgeon it is very important to know which kind of nose really requires a correction. Several studies have been done by various authors to define criteria for an ideal nose. There have been studies on measurements of nose like nasal length, nasal width, nasal index, etc. ${ }^{1,2}$ Several studies were also done on nasal angles like nasofrontal, nasofacial, and nasolabial angles. ${ }^{3,4}$ But values reported by these studies have to be considered together in evaluating an ideal nose. Some authors lately have devised a simpler way toward evaluation of an ideal nose, which is NTP. The projection of the nasal tip is the distance at which the nasal tip protrudes from the face. There are various methods of evaluating NTP. Baum ${ }^{5}$ defined NTP as the ratio between the line from tip defining point (TDP) perpendicular to the line between nasofacial and nasolabial angles that must be 1:2. Powell and Humphreys ${ }^{6}$ made it even simpler by using the same perpendicular line but the ratio must be 1:2.8. Goode method uses a right triangle to define best NTP. The first side of the triangle is a line from nasofacial angle to alar crease, the second side is a perpendicular line from TDP to this line, and the third line is on the nasal dorsum from TDP to nasion. ${ }^{7}$ Crumley and Lanser ${ }^{8}$ recommend two new ways for formulating best NTP. In Crumley1, the ratio between the line from nasion to the vermillion and upper lip's skin junction perpendicular to the line from TDP must be 3.53. Crumley2 uses a triangle just like Goode but the posterior line continues its way and reaches the mandible profile at last. The ratio between this line with the perpendicular line to it must be 4.23. However, Goode method is supposedly the best one to analyze NTP. ${ }^{9}$ In Goode's method, NTP is analyzed by measuring the line perpendicular to the facial plane to the nasal tip point/TDP divided by the nasion to TDP line. It is recommended that this value falls in the range of 0.55 to 0.6 . When this ratio is high, that means nose is projected further away from face and is considered an overprojected nose. When the reverse happens, the nose is considered underprojected. ${ }^{10}$

But, as a universal rule, body parameters vary from region to region and are different with various ethnic 
groups. Facial anthropometry among different nations is different and one of the most important factors regarding this issue is nasal shape. ${ }^{11-13}$ There has not been much work done in defining an ideal nose using NTP as a parameter in Indian population. Therefore, authors of the present study proceeded to study medical students of Velammal Medical College Hospital and Research Institute, Madurai, Tamil $\mathrm{Nadu}$, India, with an objective to derive reference values in relation to NTP of Tamil Nadu population.

\section{MATERIALS AND METHODS}

The present cross-sectional study was conducted during the months of January to April 2017. The study was approved by Institutional Ethics Committee, and was ethically conducted in accordance with Declaration of Helsinki. Written informed consent was taken from the participants before data collection. A total of 118 (43 males and 75 females) second year medical students (19-21 years of age) from Velammal Medical College Hospital and Research Institute, Madurai, Tamil Nadu, India, representing Tamil Nadu population participated in the study. Consenting students of Tamil Nadu origin were included (inclusion criteria). Individuals with noticeable facial disfigurement and with history of previous facial surgery were excluded (exclusion criteria). Sample size was calculated using sample size calculator presented as a public service of Creative Research Systems: Survey software, "The Survey System." Sample size was 118 (confidence level at 95\%, and confidence interval of 4 ) of total 142 students (population).

Goode method was used to analyze NTP. Participants were positioned in anatomical posture with head positioned in Frankfurt horizontal (FH) plane. The FH plane is defined by a line connecting the orbital (the lowest point of the infraorbital margin) and the porion (point at the upper edge of the auditory meatus) or tragion (landmark on the upper edge of the tragus). This plane can be achieved by judging the relationship of upper and lower edges of the ear to the eyebrow level and the ala level respectively. ${ }^{3}$ Lateral view photograph of face of each participant was taken. These photographs were later converted to pencil sketch photographs (using Android software) in order to get a clear outline of the lateral facial profile, as shown in Figure 1. Each such photograph was pro forma for data collection from each
Fig. 1: Pencil sketch photograph indicating segments "a" and "b" and facial plane "c"

participant. Measurements were taken using Marcus Bader Ruler software. The parameters measured were (1) segment " $a$ " (nasion to nasal TDP) and (2) segment " $b$ " (line perpendicular to the facial plane " $\mathrm{c}$ " to the nasal tip) as indicated in Figure 1.

Nasal tip projection was later calculated using the two measured values, which is b divided by a (b/a). Mean and SD were calculated. Statistical analysis was done by the application of unpaired $t$-test using GraphPad software. Significance level was assessed with $\mathrm{p}$-value $<0.05$.

\section{RESULTS}

Observed values for segment " $a$ " and " $b$ " (measurements taken in millimeters) were tabulated in a master chart. Statistical values, namely mean, SD, standard error of mean (SEM), and 95\% confidence interval $\left(\mathrm{CI}_{95}\right)$ of the difference in mean of the parameters of male $(\mathrm{m})$ and female (f) participants, were estimated. Intermediate values in calculation were t value, degrees of freedom (df), and standard error of difference (SED). Table 1 indicates statistical findings for NTP. Statistical analysis (Table 2) was done with the application of unpaired t-test to assess if there was significant difference in NTP between male and female participants. The results were significant, which means significant difference existed between male and female participants in relation to NTP.

Linear regression graph plotting was done to know if any correlation existed among segments "a" and " $b$ " of

Table 1: Statistical findings for NTP

\begin{tabular}{|c|c|c|c|c|c|c|c|c|c|}
\hline \multirow[b]{2}{*}{$n$} & \multicolumn{3}{|c|}{ Segment "a" } & \multicolumn{3}{|c|}{ Segment "b" } & \multicolumn{3}{|c|}{ Nasal tip projection (b/a) } \\
\hline & Mean & $S D$ & SEM & Mean & $S D$ & SEM & Mean & $S D$ & SEM \\
\hline Males (43) & 31.72 & 4.83 & 0.737 & 21.18 & 3.62 & 0.552 & 0.663 & 0.06 & 0.0092 \\
\hline Females (75) & 29.76 & 4.88 & 0.563 & 19.14 & 3.47 & 0.401 & 0.639 & 0.06 & 0.0069 \\
\hline Total (118) & 30.47 & 4.93 & 0.0454 & 19.88 & 3.65 & 0.336 & 0.648 & 0.06 & 0.0056 \\
\hline
\end{tabular}

SD: Standard deviation; SEM: Standard error of mean 
Table 2: Statistical analysis between male and female NTP

\begin{tabular}{lllllll}
\hline & & & Standard error of & & S-value & Statistical significance \\
\hline Segment "a" & $0.12-3.79$ & 2.1047 & 116 & 0.930 & 0.0375 & $\mathrm{~S}$ \\
Segment "b" & $0.7-3.373$ & 3.0181 & 116 & 0.675 & 0.0031 & HS \\
NTP & $0.002-0.05$ & 2.1171 & 116 & 0.011 & 0.0364 & $\mathrm{~S}$ \\
\hline
\end{tabular}

\section{S; Significant; HS: High significant}

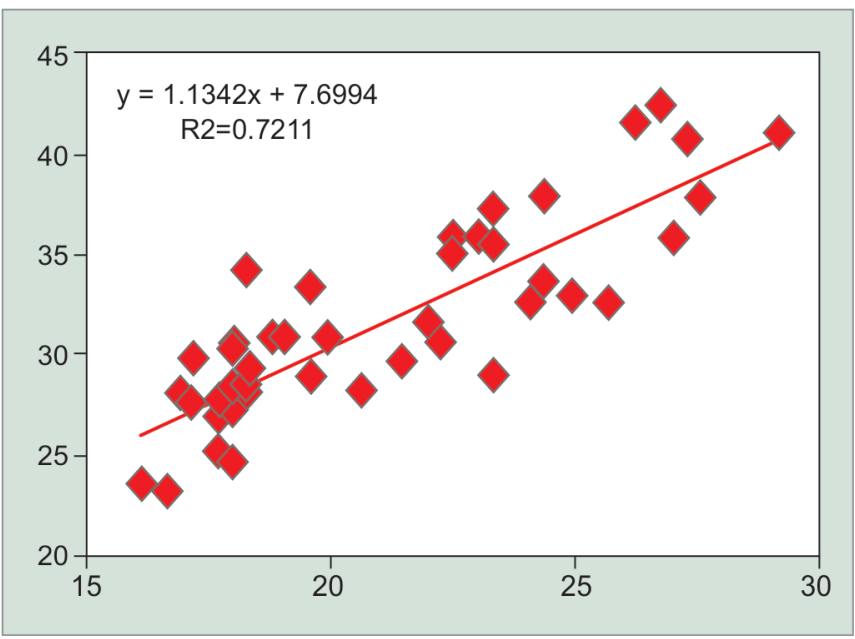

Graph 1: Linear regression graph for segments "a" (vertical axis) and "b" (horizontal axis) of males

males and females, and indeed, low positive correlation did exist between segment "a" and " $b$ " of males (Graph 1 indicates the finding). Interestingly, high positive correlation was found between segment "a" and " $b$ " of females, as indicated by Graph 2 .

\section{DISCUSSION}

Rhinoplasty is a corrective nasal surgery, where postoperative late complications result from nasal healing that sometimes causes changes in nasal morphology and function. ${ }^{14,15}$ The surgeon should anticipate these healing forces and take into account support mechanisms of the nasal tip when planning an optimal approach for surgery. ${ }^{16}$ Rhinoplasty should focus on ideal levels of stability, symmetry, rotation, and projection which resist nose healing forces. An inappropriate resection of cartilage and the use of grafts and sutures can lead to nasal tip deformities, including ptosis, alar collapse, retraction, and pinching. ${ }^{17}$ Therefore, it becomes very important for a surgeon to have an idea of the normal values of NTP for that particular region. The surgeon can thus focus on these normal values while deciding on patient suitability for rhinoplasty (patients with over- and under-projected noses will thus be obvious candidates for rhinoplasty). The surgeon can also consider these reference NTP values as target values during postoperative period.

Hardly any studies have been reported on NTP till date. There have been more speculations on NTP than actual research. However, two studies, Fagundes et al ${ }^{10}$

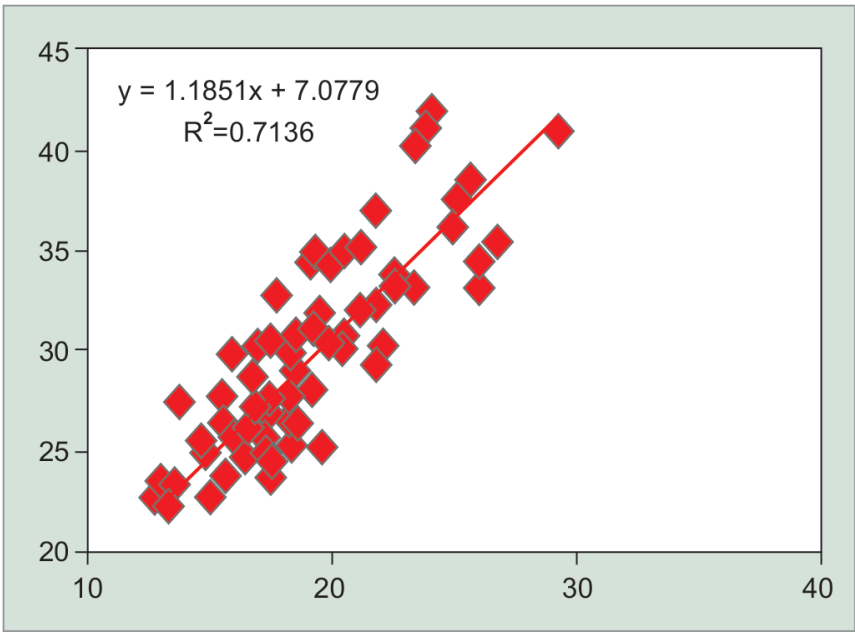

Graph 2: Linear regression graph for segments "a" (vertical axis) and "b" (horizontal axis) of females

and Mohebbi et al ${ }_{1}^{18}$ have reported on NTP lately, of which method adopted (Goode method) by the present study was the same as that by Fagundes et al. In a study by Fagundes et al, Brazilian patients with predominant Caucasian features were the participants. In that study, 27 preoperative patients were identified who were followed until postoperative period, and NTP was analyzed separately during the two periods on the same patients. The study reported NTP of 0.69 with an SD of 0.09 during preoperative period and NTP of 0.67 later. In comparison, the present study involved South Indian (never before operated) medical students, and reports NTP of 0.65 with $\mathrm{SD}$ of 0.06 . Mohebbi et $\mathrm{a}^{18}$ reported on NTP that was derived from other methods.

The only limitation of the study was inability to accurately position the participants' heads in FH plane. Even with best of efforts, it was not possible to achieve perfect positioning. More important is uniformity in positioning the heads in the same plane, which too is hard to achieve. This limitation can be overcome by using an apparatus or a mount to place the participants' heads in the FH plane.

Knowledge of normative values of external nose angles like nasofrontal, nasolabial, nasofacial, nasomental angles is quite helpful for a surgeon while planning an approach for corrective nasal surgeries. Nasal measurements and nasal indices are also equally helpful. But the authors of the present study believe that NTP, for a particular geographical area and ethnic group, is much simpler for the surgeon in these esthetic nasal surgeries. The present study is a guide for the same purpose. 


\section{CONCLUSION}

Authors conclude by reporting NTP of 0.65 (0.66 in males and 0.64 in females) with SD of 0.06 in South Indian population of Tamil Nadu region. This means males in this area have a slightly overprojected nose. It was also found that the segments considered for deriving NTP were positively correlated. This meant that long noses are overprojected than shorter ones. Last but not the least, NTP can be considered as a ratio that can be used while planning corrective nasal surgeries, and can be used in a simple and effective manner than other parameters like nasal angles and indices, and nasal morphology.

\section{CLINICAL SIGNIFICANCE}

Rhinoplasty is a corrective nasal surgery, where postoperative late complications result from nasal healing that sometimes causes changes in nasal morphology and function. The present study results will help surgeons avoid these unforeseen complications by anticipating these healing forces and take into account support mechanisms of the nasal tip when planning an optimal approach for esthetic nasal surgeries on patients, especially of our geographical area, and of the ethnic group that has been studied on. Surgeons from other parts of the world can use the present study results as reference while planning similar surgeries. Last but not the least, NTP is an easy way of evaluating patients with over- and underprojected nose while recommending rhinoplasty for these patients in whom NTP is expected to normalize postsurgery.

\section{ACKNOWLEDGMENTS}

Authors would like to thank all the students who volunteered to participate in the study. They also acknowledge the immense help received from the scholars whose articles are cited and included in references of this manuscript. Authors are also grateful to authors/editors/ publishers of all those articles, journals, and books from where the literature for this article has been reviewed and discussed.

\section{REFERENCES}

1. Sadacharan CM. Nose anthropometric study on Indian Americans and its clinical applications. Int J Adv Res Dev 2016;1(2):33-38.

2. Esomonu UG, Ude RA, Lukpata PU, Nandi EM. Anthropometric study of the nasal index of Bekwara ethnic group of cross river state, Nigeria. Scinzer J Med 2015;1(1):1-4.

3. Uzun A, Ozdemir F. Morphometric analysis of nasal shapes and angles in young adults. Braz J Otorhinolaryngol 2014 Sep-Oct;80(5):397-402.

4. Eliakim-Ikechukwu CF, Ekpo AS, Etika M, Ihentuge C, Mesembe OE. Facial aesthetic angles of the Ibo and Yoruba ethnic groups of Nigeria. IOSR J Pharm Biol Sci 2013;5(5):14-17.

5. Baum S. Introduction. Ear Nose Throat J 1982;61:426-428.

6. Powell, N.; Humphreys, B. Proportions of the aesthetic face. New York: Thieme-Stratton; 1984.

7. Simons R. Nasal tip projection. Ptosis and supratip thickening. Ear Nose Throat J 1982;61:452-455.

8. Crumley RL, Lanser M. Quantitative analysis of nasal tip projection. Laryngoscope 1988 Feb;98(2):202-208.

9. Devcic Z, Rayikanti BA, Hevia JP, Popenko NA, Karimi K, Wong BJ. Nasal tip projection and facial attractiveness. Laryngoscope 2011 Jul;121(7):1388-1394.

10. Fagundes MS, Moreira AT, Tambara EM, Tenório SB, Fraga RD, Hamerschmidt R. Objective assessment of surgical technique in rotation and nasal projection variation. Braz J Otorhinolaryngol 2016 Jan-Feb;82(1):47-55.

11. Sim RS, Smith JD, Chan AS. Comparison of the aesthetic facial proportions of southern Chinese and white women. Arch Facial Plast Surg 2000 Apr-Jun;2(2):113-120.

12. Choe KS, Yalamanchili HR, Litner JA, Sclafani AP, Quatela VC. The Korean American woman's nose: an in-depth nasal photogrammatic analysis. Arch Facial Plast Surg 2006 SepOct;8(5):319-323.

13. Choe KS, Sclafani AP, Litner JA, Yu GP, Romo T 3rd. The Korean American woman's face: anthropometric measurements and quantitative analysis of facial aesthetics. Arch Facial Plast Surg 2004 Jul-Aug;6(4):244-252.

14. Perkins S, Patel A. Endonasal suture techniques in tip rhinoplasty. Facial Plast Surg Clin North Am 2009 Feb;17(1):41-54.

15. Toriumi DM. Structure approach in rhinoplasty. Facial Plast Surg Clin North Am 2002 Feb;10(1):1-22.

16. Dobratz EJ, Tran V, Hilger PA. Comparison of techniques used to support the nasal tip and their long-term effects on tip position. Arch Facial Plast Surg 2010 May-Jun;12(3):172-179.

17. Friedman O, Koch CA, Smith WR. Functional support of the nasal tip. Facial Plast Surg 2012 Apr;28(2):225-230.

18. Mohebbi A, Jahandideh H, Faham Z, Jafari M. Defining the best nasal tip projection among Iranian women. Plast Surg Int 2016;2016:8549276. 